\title{
CONCEITOS \\ VALORATIVOS \\ NA LEITURA \\ DE TIRINHA \\ DE QUADRINHOS
}

CONCEPTOS VALORATIVOS EN LA LECTURA DE CÓMICS

EVALUATIVES CONCEPTS IN THE READING OF A COMIC STRIP

\author{
Kátia Roseane Cortez dos Santos* \\ Universidade Estadual Paulista \\ Renilson José Menegassi** \\ Universidade Estadual de Maringá
}

\begin{abstract}
RESUMO: A partir do componente valorativo como algo intrínseco ao existir humano e à linguagem, empreendemos, neste artigo, uma reflexão analítica sobre os conceitos axiológicos do dialogismo - juízo de valor, situação extraverbal, entonação - advindos dos estudos do Círculo de Bakhtin, com ênfase aos dois últimos, em específico. A reflexão tem por base uma concepção dialógica da linguagem, com destaque na abordagem sócio-histórica, e se apresenta de três formas: a) pela discussão teórica sobre axiologia; b) pela análise de um texto do gênero Tirinha de Quadrinhos, em que se investiga as noções de valor consubstanciada no texto escolhido; c) pela elaboração de perguntas de leitura para o gênero analisado, com o foco no ensino de leitura em sala de aula. Na análise da Tirinha de Quadrinhos selecionada, consideramos principalmente os enunciados verbalizados, o extraverbal e a entoação, observamos os juízos de valores diferentes sobre o lugar que a comunidade negra pode e deve ocupar em nossa sociedade.
\end{abstract}

PALAVRAS-CHAVE: Axiologia. Dialogismo. Tirinha de Quadrinhos.

RESUMEN: Partindo del componente evaluativo como algo intrínseco a la existencia humana y el lenguaje, en este artículo, llevamos a cabo una reflexión analítica sobre los conceptos axiológicos del diálogo - juicio de valor, situación extraverbal, entonación - que surgen de los estudios del Círculo de Bajtín, con énfasis en los dos últimos, específicamente. La reflexión tiene como base una concepción dialógica del lenguaje, con enfoque socio-histórico, y se presenta de tres maneras: a) mediante la

\footnotetext{
* Doutoranda do Programa de Pós-Graduação em Estudos Linguísticos da Universidade Estadual Paulista Júlio de Mesquita Filho (Unesp) - Campus de São José do Rio Preto. Bolsistado CNPq. ORCID: https://orcid.org/0000-00030395-6633.E-mail:katiacortez_@hotmail.com.

** Docente do Departamento de Teorias Linguísticas e Literárias e do Programa de Pós-Graduaça em Letras da Universidade Estadual de Maringá (UEM). Doutor em Letras pela Universidade Estadual Júlio de Mesquita Filho (Unesp). Maringá, Brasil. ORCID:https://orcid.org/0000-0001-7797-811X. E-mail: renilson@wnet.com.br. Artigodesenvolvido junto ao projeto de pesquisa "Escrita, revisão e reescrita na formação docente", com fomento da Fundação Araucária, C P $15 / 2017$
} 
discusión teórica sobre axiología; b) mediante el análisis de un texto del género cómic, en que se investigan las nociones de valor incorporadas en el texto elegido; c) mediante la elaboración de preguntas de lectura para el género analizado, centrándose en la enseñanza de la lectura en el aula. En el análisis de los cómics seleccionados, consideramos principalmente los enunciados verbalizados, el extraverbal y la entonación, y con eso observamos los diferentes juicios de valor sobre el lugar en que la comunidad negra puede y debe ocupar en nuestra sociedad.

PALABRAS CLAVE: Axiología. Dialogismo. Cómics.

ABSTRACT: Starting from the evaluative component as something intrinsic to human existence and language, in this article, we propose an analytical reflection on the axiological concepts of dialogism - value judgment, extraverbal situation, intonation arising from the studies of the Bakhtin Circle, with emphasis on the last two, in particular. The reflection is based on a dialogical conception of language, with emphasis on the socio-historical approach, and presents itself in three ways: a) by the theoretical discussion about axiology; b) by the analysis of a text of the genre Comic Strip, in which we investigate the notions of value embodied in the chosen text; c) by the elaboration of reading questions for the genre analyzed, focusing on teaching reading in the classroom. In the analysis of the selected Comic Strip, we mainly considered verbal statements, extraverbal and intonational, and we observed judgments of different values about the place that the black community can and should occupy in our society.

KEYWORDS: Axiology. Dialogism. Comic strip.

\section{CONSIDERAÇÕES INICIAIS}

Este artigo tem por objetivo apresentar uma reflexão analítica sobre os conceitos axiológicos advindos do dialogismo: entoação, situação extraverbal e julgamento de valor, a atentar-se principalmente aos dois primeiros, uma vez que entendemos que o julgamento de valor está diluído na entoação e na situação extraverbal, a formar um todo indissolúvel, uma característica da linguagem humana em seus usos. Os conceitos foram propostos pelo Círculo de Bakhtin, sendo que o componente axiológico intrínseco ao existir humano é um dos três pilares que sustentam as reflexões realizadas pelo Círculo, no que concerne à linguagem, juntamente com "a questão da unicidade e eventicidade do Ser" e "o tema da contraposição eu/outro" (FARACO, 2009, p. 18). Assim, os conceitos escolhidos, quando de suas análises no gênero Tirinha de Quadrinhos, imbricam-se, refretam-se e refletem-se, por sua essencialidade.

Dessa forma, este estudo está fundamentado em pressupostos teóricos que consideram o caráter dialógico da linguagem, com destaque à abordagem sócio-histórica, a partir dos trabalhos do Círculo de Bakhtin - especificamente as obras Voloshinov (2013) A palavra na vida e a palavra na poesia e Bakhtin (2006) Marxismo e Filosofia da Linguagem - e de outros pesquisadores que desenvolveram pesquisas nesse escopo teórico, como Faraco (2009), Dionísio (2010, 2011), Campos (2007), e Elichirigoity (2008).

Propomos também um exercício de leitura analítico de uma Tirinha de Quadrinhos, em que investigamos como os conceitos eleitos se fazem presentes e como permitem determinadas compreensões do enunciado, em específico, suas configurações verbais. Nessa perspectiva, são oferecidas questões de leitura que orientam uma possibilidade de trabalho com a leitura do enunciado, pelo viés do dialogismo, entre outras vertentes teóricas possíveis, como contribuição ao ensino de língua escrita.

\section{O COMPONENTE AXIOLÓGICO DA LINGUAGEM}

O componente axiológico é intrínseco ao existir humano, o que significa que não é possível vivermos à parte dos julgamentos de valores que nos circundam e que nos constituem. Faraco (2009), ao retomar o que é discutido por Bakhtin (1974), afirma que há dois centros de valores em nossas vidas, os quais, embora muito diferentes, relacionam-se um com o outro: o eu e o outro. Dessa forma, o mesmo referente, se visto da minha perspectiva ou da perspectiva de outrem, recebe valorações diferentes. Nesse jogo de contraposições vivemos constantemente em alteridade, princípio constitutivo dos grupos sociais. Assim, nos ensinamentos de Faraco (2009, p. 21-22, grifos do autor), “[...] Bakhtin dirá no manuscrito O autor e herói na atividade estética (p. 187-188) que viver significa tomar uma posição axiológica em cada momento, significa posicionar-se em relação a valores. Vivemos e agimos, portanto, 
num mundo saturado de valores, o interior do qual cada um dos nossos atos é um gesto axiologicamente responsivo num processo incessante e contínuo".

Em outras palavras, existem diversas axiologias às quais respondemos ativa e constantemente, seja para reiterar, concordar ou repetir, seja para discordar ou confrontar, sendo que essa resposta é sempre carregada de uma nova posição axiológica construída diante de outras posições, até porque cada indivíduo, no seu uso de linguagem, expressa a história de vida que carrega em si.

Nesse ponto, é importante ressaltar que a discussão em torno do elemento axiológico que nos constitui se apresenta primeiramente, como uma discussão filosófica, só a partir de 1926, com a chamada "virada linguística", materializada na obra Slovo v zhizni i slovo $v$ poesie $^{1}$, que o Círculo de Bakhtin passa a eleger a linguagem como ponto fundamental de suas discussões e, consequentemente, a pensar o componente axiológico na linguagem de maneira mais própria e determinada. Nessa obra, o autor discorre sobre as formas de valorações que constituem um enunciado: a entoação, o extraverbal e o juízo de valor. Ainda sobre o tema, Voloshinov (2013, p. 80, grifos do autor) comenta que "As valorações subentendidas aparecem então não como emoções individuais, senão como atos socialmente necessários e consequentes. As emoções individuais, por sua vez, somente podem acompanhar o tom principal da valoração social em sua qualidade de matriz: um 'eu’ somente pode realizar-se na palavra se se apoia nos ‘outros”.

A valoração não é fruto de um julgamento subjetivo, pessoal, desligado da realidade que nos cerca, mas se dá com base em valores já existentes em nossa sociedade, que são repetidos e reafirmados, às vezes de forma tão recorrente que nem os percebemos mais como valores construídos socialmente, mas os encaramos como naturais. Tais avaliações são, portanto, o solo comum sobre o qual construímos nossos enunciados e compreendemos ativamente os enunciados alheios.

De acordo com Faraco (2009), é comum nos escritos do Círculo que o adjetivo ideológico apareça como equivalente a axiológico, sendo que todo enunciado é, portanto, sempre ideológico, já que qualquer enunciado está sempre "na esfera de uma das ideologias (i. e., no interior de uma das áreas da atividade intelectual humana) e expressa sempre uma posição avaliativa (i.e., [...] a própria retórica da neutralidade é também uma posição axiológica)" (FARACO, 2009, p. 47). Assim, não existe enunciado neutro, porque não existe enunciado que não expresse uma posição avaliativa.

Dessa maneira, o termo "enunciado" é entendido como palavra/discurso vivo, que faz parte da realidade concreta do uso da língua, e não como uma frase composta apenas por signos linguísticos, retirados de um sistema abstrato. Sobre isso, Elichirigoity (2008, p.194) comenta: "A experiência verbal individual do homem toma forma e evolui sob o efeito da interação contínua com os enunciados individuais do outro. Bakhtin julga isso um processo de assimilação mais ou menos criativo, das palavras do outro (e não das palavras da língua)”.

Para Bakhtin, o que falamos resulta de uma interação constante com o que ouvimos e lemos em nossas relações sociais, apropriamonos de posições avaliativas, de sentidos ideológicos, não de signos linguísticos abstratos constituintes de um sistema que se situa fora da vida do discurso. Toda palavra, todas as manifestações discursivas são carregadas de sentidos ideológicos, de valores sociais.

Um dos conceitos também trabalhados é o de entonação. Este termo surge de formas diversas nas obras do Círculo, pois, de acordo com Souza (2002, p. 129), no conjunto da obra do Círculo "esse conceito aparece com as seguintes concepções: entonação, entoação, tom, acento, tonalidade, sempre em correlação com o conceito de valor - horizonte social, apreciação social e expressividade".

Para Dionísio (2011, p.175), a entonação, por sua vez, "[...] engloba as alterações no comportamento físico da voz durante a fala ou tom entendido como padrão de altura da voz (graves, agudos, timbre, qualidade) ou a prosódia como variações de altura, volume,

${ }^{1}$ Esse texto, publicado pela primeira vez em russo na revista Zvezda n. 6, recebeu uma tradução para uso didático feita por Carlos Alberto Faraco e Cristóvão Tezza, Discurso na vida e discurso na arte: sobre poética sociológica. A tradução para o português tomou como base a tradução inglesa de I. R. Titunik, Discourse in life and discourse in art: concerning sociological poetics, de 1976. Neste artigo, preferimos utilizar a tradução de João Wanderley Geraldi, A palavra na vida e a palavra na poesia: introdução ao problema da poética sociológica, de 2013, por ser mais recente. 
ritmo e tempo (velocidade de emissão), mas não se funda nessa dimensão psicobiofisiológica, nem se restringe a ela, nem tampouco a toma como objeto de estudo exclusivo".

Para melhor compreensão, outros atributos da entoação, a partir de Discurso na vida e discurso na arte (VOLOSHINOV, 1926) são também considerados:

- $\quad$ a entoação é a mais pura forma de manifestação do julgamento de valor;

- $\quad$ é o chão compartilhado entre o discurso na vida e o discurso na arte;

- $\quad$ é social por excelência;

- $\quad$ é o elo entre o discurso verbal e o contexto extraverbal;

- $\quad$ envolve os eventos da vida e o discurso verbal, formando um todo inseparável;

- $\quad$ é responsável também pela seleção dos vocábulos e pela combinação entre eles.

Já no que diz respeito à obra Marxismo e Filosofia da Linguagem (2006), a autora afirma que a entoação é abordada em sua relação com os conceitos de tema, significação e compreensão ativa, considerada como uma entoação expressiva, já em ampliação à discussão inicial. A autora também faz um apanhado sobre como a entoação é tratada no texto Os gêneros do discurso, que faz parte do livro Estética da criação verbal (2003), a apontar que é apresentada uma tipologia, não sistemática, mas que pode contribuir para a reflexão sobre esse assunto: "(1) não-entonação da palavra na língua; (2) entonação expressiva individual do outro; (3) entonação expressiva do gênero do discurso; (4) entonação gramatical; (5) entonação narrativa, exclamativa, exortativa” (DIONÍSIO, 2011 , p. 176).

Neste trabalho, consideramos entoação apenas no sentido indicado no primeiro item, uma vez que tratamos de sua relação com o extraverbal e com a avaliação, portanto, não relacionada com a palavra no sistema linguístico abstrato, mas com o discurso vivo e concreto.

Sobre o extraverbal, Campos (2007, p.132) faz o seguinte apontamento:

\begin{abstract}
É preciso compreender a enunciação como o produto da interação de dois indivíduos socialmente organizados. A enunciação não se encerra na palavra, na fala. É necessário considerar a situação extraverbal, ou seja, a enunciação está carregada de ideias presumidas. E o presumido somente poderá ser entendido no contexto do enunciado, ou melhor, na situação extraverbal. Só se compreende de maneira ampla o enunciado na medida em que, metodologicamente, assume que os sentidos das palavras são dados na história.
\end{abstract}

Assim, se consideramos que o enunciado é sempre único e irrepetível, não podemos acreditar que sua significação esteja calcada apenas em seu conteúdo puramente linguístico, de um determinado momento, uma vez que pode ser reproduzido indefinidamente. Quando dizemos que cada enunciado possui uma significação própria, estamos com isso reiterando o extraverbal como elemento essencial para a produção e para a compreensão de um discurso. De acordo com Voloshinov (2013), o contexto extraverbal do enunciado compreende três fatores:

1) um horizonte espacial compartilhado por ambos os falantes (a unidade do visível [...]); 2) o conhecimento e a compreensão comum da situação, igualmente compartilhado pelos dois, e, finalmente, 3) a valoração compartilhada pelos dois, desta situação. (VOLOSHINOV, 2013, p. 78, grifos do autor)

O extraverbal, portanto, compreende os elementos imediatos da interação, como o local em que ela se dá, o que os interlocutores estão vendo quando estão engajados em determinada interação, como eles se expressam facial e corporalmente, entre outros; ou pode ser expandido local e temporalmente e compreender nações, classes, culturas, décadas, séculos etc. Além disso, o extraverbal também está relacionado ao que os interlocutores sabem em comum, ao que compreendem conjuntamente sobre o que está sendo dito. Por fim, para que a interação seja bem-sucedida, é preciso que os interlocutores partilhem os valores envolvidos nos enunciados proferidos e tenham uma avaliação comum sobre aquela situação de interação. 
Diante do que foi exposto nesta seção, compreendemos "porque um julgamento de valor ou avaliação 'encontra sua mais pura expressão na entonação', por consequência reafirma-se que esta última é 'um elo firme entre o discurso verbal e o contexto extraverbal'” (DIONÍSIO, 2010, p. 53). Assim, entonação, extraverbal e julgamento de valor são conceitos que funcionam em conjunto e constituem a nossa linguagem e o nosso "existir humano".

Uma exposição mais completa sobre os elementos valorativos da língua contempla, também, outros aspectos conceituais do dialogismo, como horizonte apreciativo, ideologia e signo ideológico, presentes em Bakhtin (2006) e Voloshinov (2013). Por uma questão de espaço neste texto, esses elementos não são discutidos, mesmo cientes do risco lacunar em que incorremos.

\section{OS CONCEITOS AXIOLÓGICOS EM ANÁLISE}

Nesta seção, analisamos um texto do gênero Tirinha de Quadrinhos com base nos conceitos axiológicos, a focalizar, principalmente, o extraverbal e a entoação. Antes disso, é importante fazermos algumas considerações sobre a fonte da tirinha. Ressaltamos que a análise empreendida aqui não considera os fatores pragmáticos (ou contexto imediato) de produção da tirinha no que concerne ao produtor, uma vez que não temos acesso a essa informação, pois a tirinha foi retirada da rede social Facebook, na qual foi compartilhada por diversas pessoas em diferentes datas. Como veremos no decorrer desta seção, a falta desse dado não compromete a análise pretendida, visto que a temática do texto está relacionada ao nosso contexto social atual, mas não se refere a um acontecimento em específico.

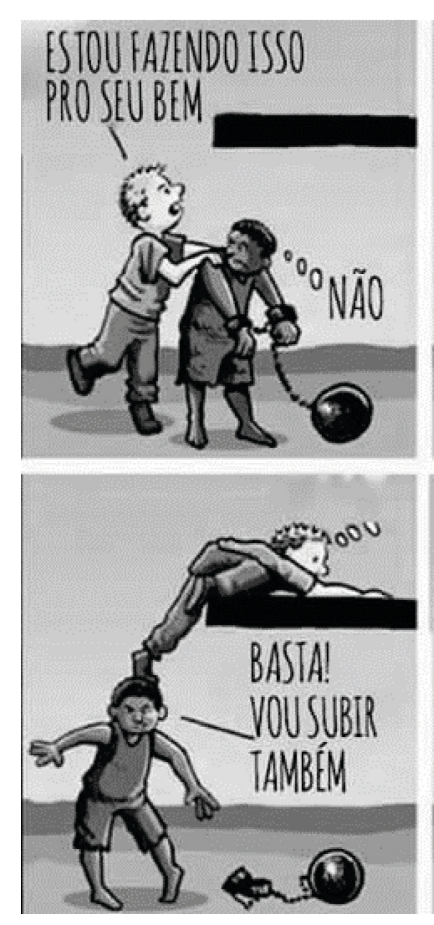

Figura 1: Tirinha
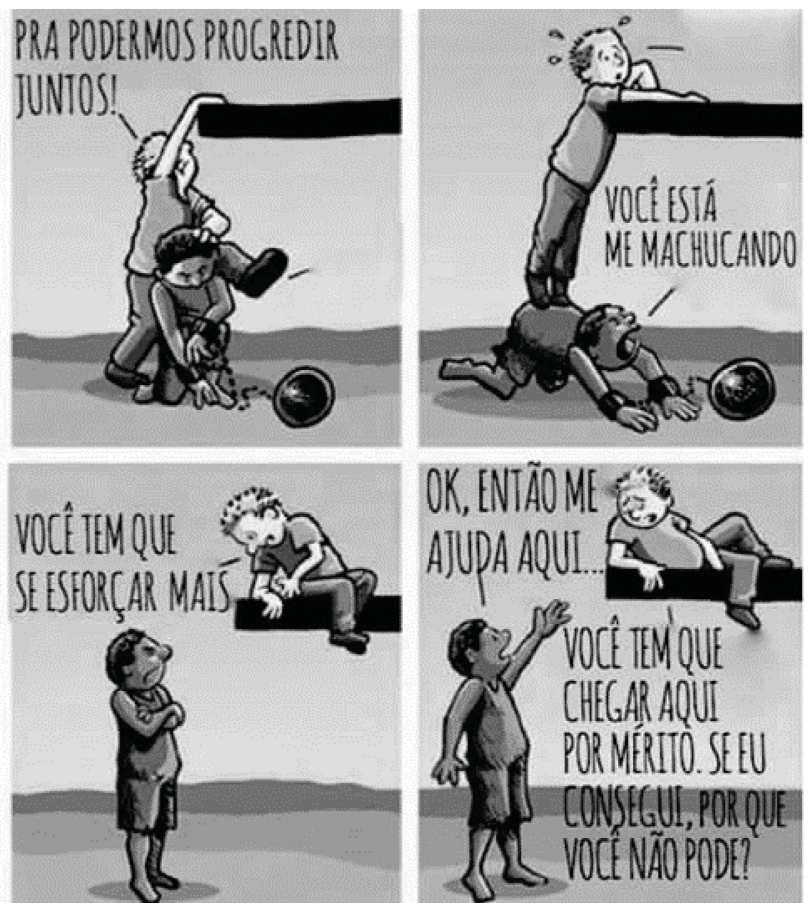

Fonte: Facebook (2020)

Para tornar nosso trabalho mais sistemático, optamos por fazer um exame quadro a quadro, a explorar tanto seus elementos verbais quanto os elementos não verbais, e, ao final, apresentamos comentários mais gerais acerca do nosso objeto de análise. Para uma melhor compreensão da análise, já adiantamos que o desenrolar da narrativa contada na Tirinha pode ser entendido como um paralelo ao desenvolvimento histórico de nossa sociedade, sendo que cada quadro representa um momento histórico importante na relação entre homens brancos e negros.

Observe o quadro 1: 
Figura 2: Quadro 1 da Tirinha

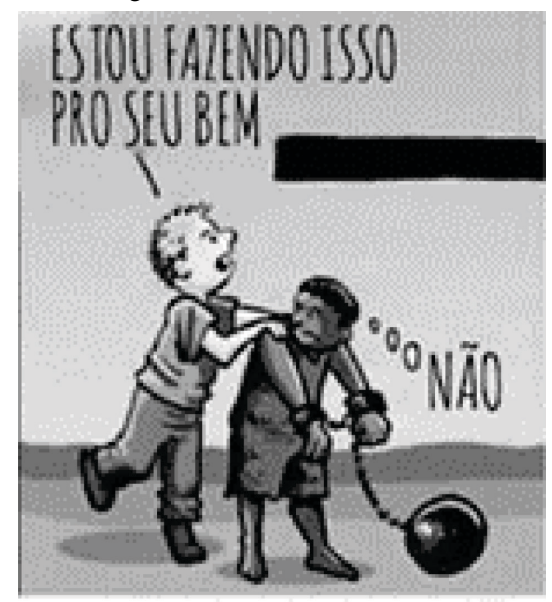

Fonte: Facebook (2020)

No primeiro quadro, notamos que a fala do homem branco pode ser entoada de uma maneira irritada, impaciente. Isso é demonstrado por meio de sua expressão facial (sobrancelhas arqueadas) e pela sua postura corporal (falando ao mesmo tempo em que tenta subir nas costas do homem negro, com um dos pés já fora do chão), o que permite inferir que a entoação de leitura é de alguém que está irritado, ou até mesmo bravo. A fala do homem negro possui um tom de indignação, como é possível notar pelo seu rosto carrancudo, de quem não está nada satisfeito. Essa fala é, na verdade, um pensamento, que pode ser identificado por causa da marca específica do gênero para expressar essa maneira de comunicação, em forma de três círculos até que a fala de manifeste. Assim, podemos afirmar que a entoação não está relacionada somente ao caráter físico do som de nossa voz, no caso, o caráter escrito, mas à acústica mental que elaboramos quanto falamos ou ouvimos, decorrente da união de nossos juízos de valores já estabelecidos pelo corpo social, observada pelos elementos notacionais descritos da Tirinha.

Podemos interpretar o pensamento do homem negro considerando que não pode se expressar em voz alta devido às condições sócio-históricas a que a imagem desse quadro faz referência: um período em que os brancos sobrepujavam os negros e os escravizavam, apontado pelo homem negro preso a uma bola de chumbo, uma vez que seus clamores não eram ouvidos em nossa sociedade, menos ainda pelo homem branco.

No que se refere ao conteúdo do dizer do homem branco, observamos o dêitico "isso" ("ESTOU FAZENDO ISSO PRO SEU BEM"). A que esse pronome se refere? Aqui, podemos estabelecer duas referências, uma relacionada ao contexto imediato da tirinha, outra ao contexto amplo do discurso proferido, já que "a situação social mais imediata e o meio social mais amplo determinam completamente e, por assim dizer, a partir do seu próprio interior, a estrutura da enunciação." (BAKHTIN, 2006, p. 115-116, grifos do autor).

No primeiro caso, "ISSO" indica o ato de subir nas costas do homem negro para se alcançar o patamar que está acima de ambos, a meta - que simbolicamente pode representar vários elementos: status, dinheiro, direitos civis, bem-estar social, enfim, tudo que foi (e em muitos casos ainda é) negado aos negros. Já o outro referente se encontra fora dos limites do texto, ou seja, para além de seu contexto; "ESTOU FAZENDO ISSO PRO SEU BEM", em outras palavras, significa, hipoteticamente, "Estou te explorando, maltratando-te, destituindo-te de seus direitos e de suas oportunidades, tudo isso pro seu bem, pois é assim que se faz com pessoa negra.".

De acordo com Voloshinov (2013, p. 91, grifos do autor), "Ali onde a análise linguística vê as palavras tão solitárias e as inter-relações entre seus aspectos abstratos (fonéticos, morfológicos, sintáticos e outros), para uma percepção artística viva e para uma análise sociológica concreta se manifestam as relações entre a gente, relações somente refletidas e fixas no material verbal".

Assim, o que encontramos no discurso proferido pelo homem branco não é apenas um conjunto de palavras cada qual com seus significados abstratos, mas um discurso carregado de sentidos axiológicos, em que o extraverbal e a entonação permitem 
compreender os sentidos possíveis da comunicação estabelecida. Sentidos que não são externos à realidade, mas, sim, imbrincados em discursos já ditos que permeiam a nossa sociedade e revelam relações sociais, no caso da Tirinha, relações de opressão. A fala do homem branco está inundada de outras falas, ditas em outros contextos, discursos de paternalismo hipócrita, de falsa proteção, que relevam formas camufladas de dominação: "Não são palavras o que pronunciamos ou escutamos, mas verdades ou mentiras, coisas boas ou más, importantes ou triviais, agradáveis ou desagradáveis, etc. A palavra está sempre carregada de um conteúdo ou de um sentido ideológico ou vivencial"(BAKHTIN, 2006, p. 96, grifos do autor).

Essas mesmas palavras podem tomar outros sentidos, porém, no contexto enunciativo em que aparece, sua entonação é caracterizada pelos elementos não verbais apresentados, em conjunto com as valorações que trazemos das situações extraverbais vivenciadas anteriormente. Assim, é possível observamos como a entonação é uma das chaves para a compreensão de sentidos de um enunciado.

Observe o quadro 2:

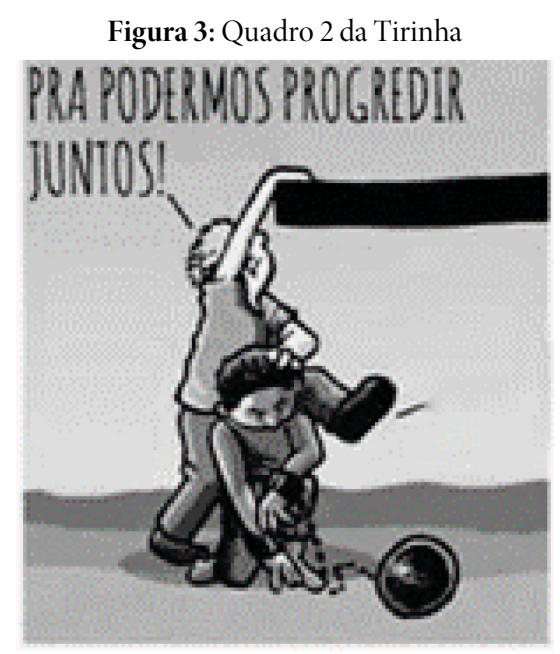

Fonte: Facebook (12 nov. 2020)

No segundo quadro da tirinha, o homem branco segue com seu discurso que visa justificar suas atitudes com argumentos aparentemente sustentados no senso coletivo, de bem comum (“PRA PODERMOS PROGREDIR JUNTOS!"). Enquanto isso, vemos o homem negro numa posição de servidão, ainda preso na bola de chumbo. Ao levarmos em consideração os dizeres de Voloshinov (2013) de que a situação é constitutiva do enunciado e de que este é composto por uma parte percebida e por uma parte presumida, podemos interpretar que, no momento histórico ao qual esse quadro faz referência, os negros, mesmo indignados pela situação em que viviam, ainda não conseguiam lutar contra sua exploração de maneira efetiva. Claro que não podemos desconsiderar as inúmeras revoltas empreendidas pelos negros escravizados e os diversos empreendimentos individuais que foram levados a cabo por tais pessoas, entretanto, ainda não havia um movimento articulado e forte o suficiente para permitir que alguma reação mais enérgica fosse tomada em prol da população negra como um todo. De todo modo, a roupa do homem branco demonstra que é um homem atual, por outro lado, a roupa do homem negro é típica de um escravo em cativeiro. Já essa diferença de vestimenta nos permite notar que os negros continuam sendo vistos do mesmo jeito que foram há anos, como escravos e subalternos. O homem branco também é visto de sua maneira histórica, porém atualizado pela vestimenta. Essas marcas axiológicas nos levam a crer que os valores continuam os mesmos com o passar dos tempos. De acordo com Elichirigoity (2008, p. 184), fundamentada pelo Círculo de Bakhtin, "a expressão exterior, na maior parte dos casos, prolonga e esclarece a orientação tomada pelo discurso interior, e as entoações que ele contém”, isto é, aquilo que verbalizamos, em um enunciado falado ou escrito, geralmente é resultado de um discurso que já foi previamente entoado internamente, em nossa mente, e essa entoação não é dada de maneira subjetiva, mas, sim, a partir de juízos de valores construídos socialmente, provindos de outros enunciados proferidos em diversos outros contextos (VOLOSHINOV, 2013).

No caso da Tirinha que estamos analisando, podemos notar esse processo no quadro 3 : 
Figura 4: Quadro 3 da Tirinha

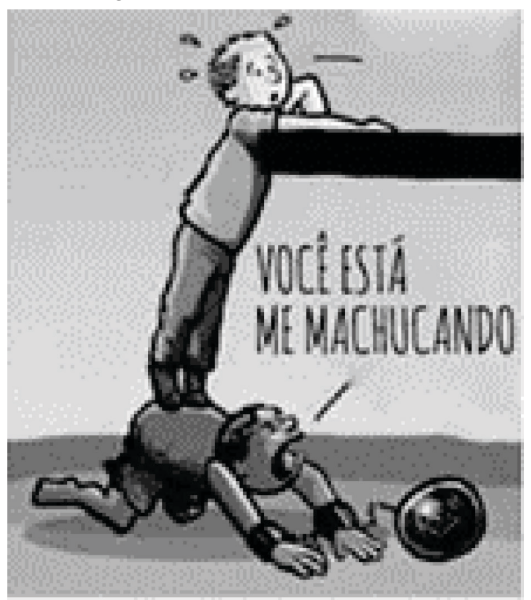

Fonte: Facebook (2020)

No terceiro quadro, pela primeira vez, o silêncio por parte do homem negro, ou melhor, seu silenciamento, é quebrado. A personagem externaliza pela fala "VOCÊ ESTÁ ME MACHUCANDO" um discurso interno entoado com nuances de indignação, raiva e revolta, o qual já foi pensado durante muito tempo, em várias situações, mas que só naquele momento veio à tona. Tal entoação pode ser percebida pela expressão facial do homem negro, com a boca bem aberta, como em um grito, e sua posição prostrada, quase escorregando, o que dá a entender que ele não está confortável ao servir de "escada" para o homem branco.

Diante dessa fala inesperada, o homem branco fica surpreso: sobrancelhas arqueadas, gotas em torno de seu rosto - marca típica das Tirinhas de Quadrinhos para indicar surpresa, confusão - e nenhuma fala. Não era esperado que o homem negro se pronunciasse, afinal o homem branco "estava fazendo isso para o bem de todos". Lembramos que tudo isso só pode ser inferido porque levamos em consideração a afirmação de Voloshinov (2013, p. 82, grifos do autor) de que "a entoação sempre se encontra no limite entre o verbal e o extraverbal, entre o dito e o não dito", a qual podemos compreender no contexto da Tirinha de duas formas:

a) a entoação está presente também no extraverbal imediato, isto é, nas expressões faciais e corporais das personagens, como vem sendo demonstrado, sem a necessidade de haver um discursos proferido externamente para que possamos compreender o que está se passando - podemos aqui lembrar da situação que Voloshinov (2013) expõem para explicar esse ponto: duas pessoas em uma sala e uma dela diz "Bem", o que, devido aos fatores extraverbais envolvidos, torna-se um enunciado completamente compreensível para os participantes daquele diálogo;

b) a entoação permite a identificação de discursos outros que perpassam o enunciado presente, ou seja, as ideologias subjacentes ao discurso, o que é não verbal e não dito naquela determinada enunciação, mas que foi verbal e dito em outras enunciações. É possível compreender o valor de raiva e indignação na fala do homem negro se considerarmos, por exemplo, as diversas revoltas empreendidas pelos escravos, que não aceitaram passivamente o fato de os homens brancos estarem a machucálos.

Observe o quadro 4: 
Figura 5: Quadro 4 da Tirinha

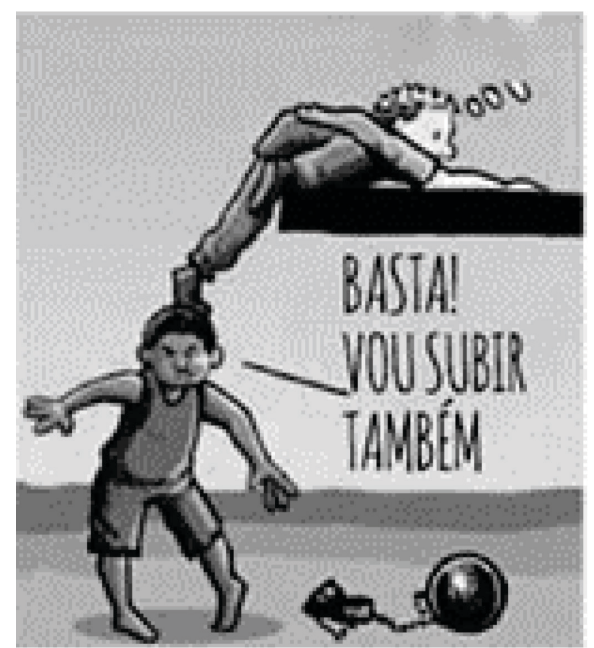

Fonte: Facebook (2020)

No quarto quadro da Tirinha, temos a consolidação daquilo que vinha sendo construído ao longo do texto - e simbolicamente, ao longo da História: o homem negro se levanta e profere "BASTA!", que podemos entender, observando os quadros - momentos históricos - anteriores, como um grito hipotético de autoridade "Estou dando um basta a toda a situação de opressão que tenho vivido”. Nesse ponto, vale indicar o que é apresentado por Dionísio (2010, p.57):

Ainda que na modalidade oral a faceta mais conhecida da ento(n)ação (ritmo, timbre, intensidade, duração, altura de voz, pausa, silêncios, hesitações, ruídos, etc.) seja bastante perceptível, sua concepção ampliada cobre a modalidade escrita, considerando, por exemplo, a seleção dos vocábulos (menos dos dicionários e mais das falas dos outros como decorrência de posicionamentos avaliativos e valorativos) bem como a própria combinação (sintaxe) entre eles.

Diante disso, percebemos como a seleção do termo "BASTA" é importante para que entendamos o enunciado com a força valorativa necessária. Se fizermos o breve exercício de trocar o termo por outro semanticamente equivalente, como "chega!" ou "pare!", notaremos que os últimos não evocam uma imagem de autoridade em relação ao sujeito que os pronunciam, "BASTA", por sua vez, remete-nos a uma figura hierarquicamente mais alta, que tem não só a possibilidade de ordenar que algo cesse, mas o poder e o direito para tanto. Além disso, esse "BASTA" é acompanhado de uma resolução: "VOU SUBIR TAMBÉM" e da libertação da bola de chumbo, ou seja, da libertação das amarras físicas e sociais que impediam a comunidade negra de lutar por seus direitos, o que, em um paralelo histórico, pode ser entendido como o momento de abolição da escravidão. Vale ressaltar que essa leitura só é possível devido ao extraverbal, o conjuntamente conhecido, o juízo de valor produzido anteriormente pela sociedade. Por outro lado, vemos o homem branco alcançando sua "meta" e a marcação gráfica (três círculos) de que ele está pensando em algo. Qual seria esse pensamento?

A resposta para essa pergunta é dada no próximo quadro. Observe: 
Figura 6: Quadro 5 da Tirinha

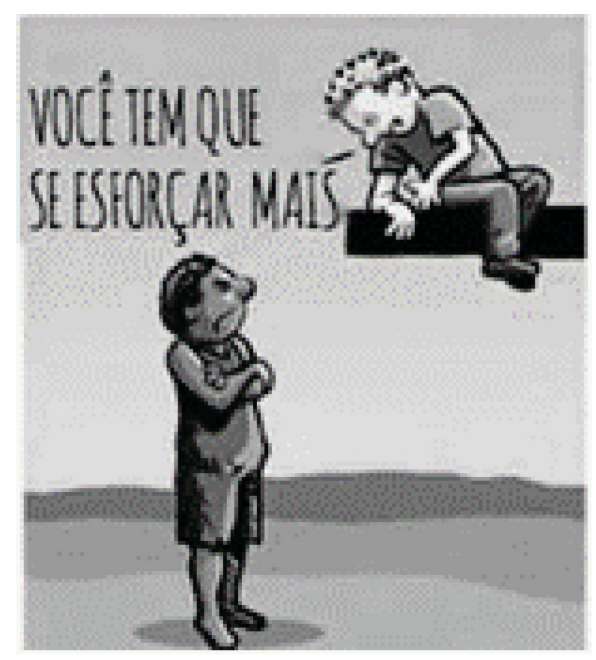

Fonte: Facebook (2020)

No quinto quadro, o homem branco declara "VOCÊ TEM QUE SE ESFORÇAR MAIS", com uma entoação aparentemente condescendente, quase paternal, como é possível perceber pela sua expressão facial calma e pela posição de suas mãos: uma apoiada de forma relaxada no patamar e outra fazendo um gesto comum de quando se dá alguma explicação para uma criança ou alguém que se julga estar numa escala intelectual inferior. Entretanto, quando analisamos mais cuidadosamente o que é expresso pela personagem, notamos uma ordem "VOCÊ TEM QUE". Dessa forma, entendemos no que o homem branco estava pensando no quadro anterior: em uma nova maneira de convencer o homem negro de que não há exploração por parte do homem branco, de que não existe desigualdade de oportunidades, de que é possível para homem negro alcançar o mesmo patamar que ele com a simples ação de se esforçar mais.

Voloshinov (2013, p. 85, grifos do autor) afirma que

[...] a entoação e o gesto são ativos e objetivos por sua natureza e tendência. Não só expressam um estado passivo de ânimo do falante, mas implicam sempre uma relação viva, enérgica, que vai até o mundo exterior e até o mio social circundante, no confronto com os inimigos, os amigos, os aliados. Entonando e gesticulando, o homem ocupa uma posição social ativa com respeito aos valores determinados, determinada pelas mesmas condições de sua existência social.

Em outras palavras, a entoação e o extraverbal, nesse momento entendido como aquilo que não é verbalizado, mas que contribui para o entendimento do enunciado, como as expressões faciais, posição corporal, o horizonte espacial comum entre os interlocutores etc., constituem-se em uma relação direta com o mundo no qual se inserem. O diálogo não ocorre apenas de um interlocutor para o outro, mas do interlocutor em relação aos valores de dado contexto sócio histórico, que são diferentes de acordo com a posição social que ele ocupa. Um exemplo disso na tirinha está no quinto quadro, quando o homem negro, embora não verbalize sua opinião a respeito do que o homem branco diz, utiliza de uma linguagem corporal para expressar sua desaprovação. Ele demonstra uma expressão facial de aborrecimento e os braços cruzados, em um sinal de não aceitação do discurso do homem branco. Essa atitude do homem negro só é possível, porque, agora, no momento sócio-histórico que esse quadro representa, a comunidade negra está na posição de recusar a ideologia da meritocracia que a população branca está tentando transmitir.

Observe o quadro 6: 
Figura 7: Quadro 6 da Tirinha

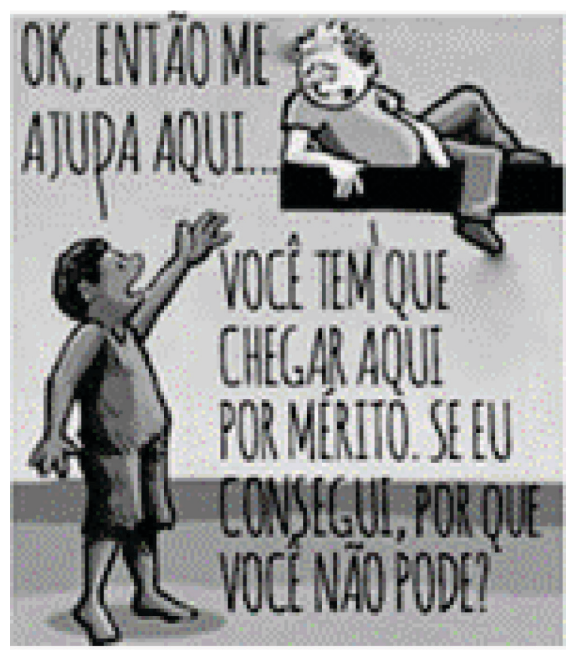

Fonte: Facebook (2020)

No sexto e último quadro, temos o homem negro com a mão estendida proferindo os seguintes dizeres "OK, ENTÃO ME AJUDA AQUI...". Na posição de leitores dessa tirinha, para entoarmos, darmos valores de forma coerente esse enunciado, precisamos considerar primordialmente alguns aspectos: a trajetória da personagem negra durante a narrativa; a trajetória histórica à qual a narrativa faz referência; e o nosso contexto sócio-histórico atual, no qual a tirinha foi produzida e ao qual o sexto quadro faz referência. Nas palavras de Bakhtin (2006, p.115), "[...] na maior parte dos casos, é preciso supor, além disso, um certo horizonte social definido e estabelecido que determina a criação ideológica do grupo social e da época a que pertencemos, um horizonte contemporâneo da nossa literatura, da nossa ciência, da nossa moral, do nosso direito"

Isso porque uma leitura superficial poderia interpretar a fala do homem negro nesse quadro como um pedido de alguém que se coloca em uma posição subalterna e precisa da ajuda de um outrem que se encontra numa posição privilegiada. Embora tal leitura não esteja completamente equivocada, uma vez que o homem branco poderia, sim, auxiliar o homem negro nessa escalada simbólica, podemos valorar o enunciado de outra forma: o homem negro, depois de escutar o novo argumento elaborado pelo homem branco, não o aceita passivamente, mas persiste na luta, dessa vez por meio de uma provocação, de um contra-argumento. Primeiro o silêncio (quadro um e dois), depois a fúria (quadro três), mais tarde a iniciativa (quadro quatro) e agora o diálogo (quadro seis).

No entanto, esse tom da narrativa, de certa forma otimista, é quebrado quando o leitor se depara com a fala proferida pelo homem branco "VOCÊ TEM QUE CHEGAR AQUI POR MÉRITO. SE EU CONSEGUI, POR QUE VOCÊ NÃO PODE?". Alguns aspectos são aqui observados sobre o enunciado. Primeiramente, sobre seu aspecto extraverbal, podemos notar a posição relaxada do homem branco, sua tranquilidade, sua expressão facial de despreocupação, ironia, talvez. Isso porque, considerando o extraverbal no sentido mais amplo, nós, leitores, sabemos que, em nossa sociedade, a elite branca - não entraremos aqui na discussão sobre classe social, mas ela se aplicaria de forma muito produtiva à análise - mantém-se confortavelmente em suas posições, ainda pouco ameaçada pelas lutas sociais, considerando que a equidade ainda é um longo e árduo caminho a trilhar, embora já se tenham alcançadas inúmeras vitórias.

Outro aspecto que podemos ressaltar sobre a fala que encerra o texto analisado é o fato de ela ser um questionamento, o qual possui dois interlocutores: o personagem negro e o leitor da tirinha. É este o pensamento que vai se fixar na mente do leitor: "Por que o homem negro não pode chegar ao mesmo patamar que o homem branco?". Entretanto, é uma pergunta para a qual o autor do texto já apresenta a resposta. Se o leitor trilhar novamente o percurso histórico demonstrado na tirinha, ele perceberá que todo o desenvolvimento dos quadros o leva a respostas próximas de: o homem negro não consegue chegar ao mesmo patamar que o homem branco devido a uma história de silenciamento, de exploração, de opressão, de castração das possibilidades, de discursos que falsamente pregavam o bem comum. E quando isso deixou de funcionar, criou-se o discurso da meritocracia e do esforço 
individual. Nesse sentido, a narrativa se torna cíclica: para responder a pergunta ao final, deve-se retornar ao início da história e da História da sociedade ocidental em relação ao tratamento do homem negro.

A tirinha também nos permite refletir sobre a dupla orientação da entoação. De acordo com Voloshinov (2013, p. 85), ela é orientada em duas direções: "com respeito ao ouvinte enquanto aliado ou testemunha, e com respeito ao objeto da enunciação como se fosse um terceiro participante vivo; a entonação o molesta, o acaricia, rebaixa ou engrandece". Dessa forma, podemos afirmar que, por meio das personagens, o autor do texto entoa seu enunciado tanto em direção ao leitor do texto (quando as personagens discutem entre si, estão na verdade discutindo conosco, leitores), quanto em direção à temática da Tirinha, sendo que podemos perceber uma crítica à opressão da população branca sobre a negra, tanto aquela efetuada de uma forma mais explícita (como vemos do primeiro ao quarto quadro), quanto à opressão camuflada em discurso de meritocracia.

\section{O VALOR A PARTIR DE QUESTÕES DE LEITURA}

Adotamos, neste trabalho, a perspectiva de que a utilização de questões de leitura é uma estratégia adequada para o desenvolvimento de habilidades de compreensão e de intepretação de textos, a promover o aumento da capacidade crítica e reflexiva do leitor, a considerar a inserção dos valores analisados e discutidos sobre o enunciado aqui apresentado. Pensando nisso e considerando a importância de uma leitura que leve em conta a axiologia, elaboramos perguntas sobre a tirinha analisada neste artigo, as quais podem auxiliar na construção de uma leitura coerente, ao se pensar numa situação de ensino. Ponderando que a leitura ocorre de uma forma linear no enunciado da Tirinha, a ordem das questões foi estabelecida de acordo com a ordem dos quadros da tirinha, na sequência narrativa do texto. A seguir, apresentamos as perguntas e, logo abaixo, explicamos como elas podem auxiliar na leitura desse texto.

1- No primeiro quadro, o que o homem branco faz com o homem negro?

2- $\quad$ O que indicam os três círculos ao lado da palavra "NÃO"?

3- No terceiro quadro, a expressão do homem branco e as gotas em seu rosto indicam qual expressão?

4- No quarto quadro, o que pensa o homem branco ao subir no patamar?

5- Qual é o efeito de sentido do ponto de exclamação junto à palavra "BASTA!"?

6- No quinto quadro, por que o homem negro está com braços cruzados, com expressão de bravo?

7- $\quad$ Como o homem branco subiu no patamar?

8- $\quad$ Por que o homem branco não ajudou o homem negro a subir no patamar?

9- $\quad$ A partir da leitura da Tirinha como um todo, explique por que o homem negro não subiu no mesmo patamar em que está o homem branco.

As perguntas apresentadas abordam vários aspectos do texto relacionados aos conceitos axiológicos aqui discutidos. Algumas trabalham a entoação, a indagar sobre elementos gráficos próprios do gênero Tinha de Quadrinhos, como é o caso das questões $2 \mathrm{e}$ 3 , as quais pretendem fazer com que se compreenda quando a personagem de uma tirinha está apenas pensando algo e não falando e que sinais ao redor do rosto de uma personagem indicam determinadas emoções. Outras questões trabalham no sentido de promover a construção de uma entoação para as falas (ou gestos) das personagens, com base no conteúdo extraverbal reconhecido por meio das expressões faciais e da linguagem corporal, como é explorado nas questões 3 e 6 . É possível observar que a questão 5 também está relacionada à entoação; entretanto, nesse caso, o leitor é levado a observar como a pontuação é um recurso importante na escrita para a construção de uma entoação para os dizeres de uma personagem.

Outro ponto que observamos quando da elaboração das questões foi o fato de que, no gênero Tirinha, verbal e não verbal estabelecem uma relação extremamente importante. Para exemplificar isso, trouxemos o questionamento número 1, que buscar fazer com que o leitor reflita sobre o dêitico "isso" ("ESTOU FAZENDO ISSO PRO SEU BEM"), reconhecendo que o referente para esse pronome não está em um enunciado anterior, mas, na própria imagem (o homem branco subindo nas costas do homem negro). Além disso, esse dêitico também pode ser interpretado para além do contexto imediato, em um sentido metafórico, em que "ESTOU FAZENDO ISSO" significaria em hipótese “Estou te explorando”. 
A questão 4, por sua vez, buscar promover a capacidade de o leitor realizar inferências e relacionar as ações anteriores com o restante da narrativa. Ao perguntarmos sobre o que a personagem poderia estar pensando, o leitor é levado a refletir sobre o que havia ocorrido antes na história e sobre o que a personagem expressa no quadro seguinte em decorrência do seu pensamento. Essa inferência, assim como várias outras feitas ao longo da leitura, demonstra como estamos o tempo todo construindo juízos de valores sobre a maneira como as pessoas pensam e agem em nossa sociedade, sendo que essa construção requer, é claro, a consideração do conteúdo extraverbal existente.

O trabalho com juízos de valores também é realizado nas questões 7 e 8 , nas quais o leitor é chamado a relacionar o que está explicitado na tirinha, isto é, a materialidade do texto, tanto os elementos verbais quanto os não verbais, com o conteúdo extraverbal que envolve o texto. Ele deve refletir sobre os conteúdos axiológicos/ideológicos sobre os quais os discursos apresentados na tirinha são construídos, além do que, a partir dessas questões, o leitor também pode expressar seus próprios juízos de valor e pensar o texto para além de sua mensagem superficial, já que a Tirinha pode ser lida metaforicamente.

A última questão recai justamente sobre o ponto crucial abordado na Tirinha. Esse último exercício de leitura representa a culminação de toda a reflexão feita ao longo das perguntas anteriores. A resposta para essa pergunta não é óbvia e exige que o leitor retorne ao início da Tirinha, observando as ações das personagens e os julgamentos de valor implicados nessas ações.

\section{CONSIDERAÇÕES FINAIS}

A partir do estudo empreendido sobre os conceitos axiológicos propostos pelo dialogismo, com ênfase na entoação e no extraverbal, observamos como estão intrinsicamente associados, apresentando-se como elementos constitutivos de nossa linguagem. Um enunciado jamais é neutro, uma vez que sempre indica determinada posição axiológica/valorativa/ideológica e trava um diálogo com diversas outras posições, com as quais pode concordar ou discordar, mas em relação às quais pode nunca ser indiferente.

Neste trabalho, também realizamos um exercício analítico em torno de um texto do gênero tirinha, quando pudemos investigar a axiologia posta em prática. Por meio dos enunciados verbalizados, do extraverbal (tanto em seu sentido mais estrito quanto no sentido amplo) e da entoação, foi possível perceber juízos de valores distintos sobre a posição que a comunidade negra pode e deve ocupar em nossa sociedade. Observamos pelo menos três perspectivas: a da personagem branca (representando a elite branca em nosso país), a da personagem negra (representante da comunidade negra) e a do autor da tirinha, o qual critica a visão opressora e se solidariza com a luta empreendida pela parte oprimida. Além disso, o professor, no trabalho com a tirinha em sala de aula, pode também explorar os juízos de valor dos alunos/leitores, que podem estar de acordo com uma das posições valorativas expostas ou, ainda, apresentar uma compreensão distinta.

Ainda no que concerne ao trabalho com a leitura do enunciado da tirinha objeto de nosso estudo, são oferecidas nove questões a contribuir para a exploração dos elementos valorativos ali constituídos, visando à construção de uma possibilidade de leitura relacionada ao ensino de língua escrita. Tais perguntas abordam o extraverbal e a entoação em vários aspectos: características próprias do gênero tirinha, como balões de falas; linguagem não verbal, facial, corporal; e algumas ideologias que permeiam nossa sociedade; tudo isso buscando auxiliar o leitor a ter uma compreensão valorativa/crítica do texto escolhido.

Dessa forma, ao nos fundamentarmos em pressupostos teóricos que concebem a linguagem como dialógica, com ênfase em uma abordagem sócio-histórica, contribuímos com a compreensão dos conceitos axiológicos do Círculo de Bakhtin, com os estudos sobre análise de textos do gênero Tirinha de Quadrinhos e o sua possibilidade de leitura ao se considerar a axiologia própria que há nele, mostrando-se um componente essencial da linguagem a ser entendida e analisada nos enunciados que circulam na sociedade. 


\section{REFERÊNCIAS}

BAKHTIN, M. Toward a methodology for the human sciences. In: BAKHTIN, M. Speech Genres \& other late essays. Austin, TX: University of Texas Press, 1974. p. 159-172.

BAKHTIN, M. Marxismo e filosofia da linguagem. 12. ed. São Paulo: Hucitec, 2006.

CAMPOS, N. de. Discurso: lugar de produção de sentidos e de luta pela verdade. Publ. UEPG Humanit. Sci., Appl. Soc. Sci., Linguist., Lett. Arts, Ponta Grossa, v. 15, n. 2, p. 129-138, dez. 2007.

DIONÍSIO, M. T..A questão do valor na linguagem para (o círculo de) Bakhtin. 2010. 90 f. Dissertação (Mestrado) - Programa de Pós-graduação em Estudos Linguísticos, Universidade Federal do Espírito Santo, Vitória, 2010.

DIONÍSIO, M. T. A questão do valor na linguagem para (o círculo de) Bakhtin. PERcursos Linguísticos. Vitória (ES). v. 3, n. 1 (edição especial), p. 171-182.2011.

ELICHIRIGOITY, M. T. P. A formação do sentido e da identidade na visão bakhtiniana. Cadernos de Letras da UFF - Dossiê: Literatura, língua e identidade, n. 34, p. 181-206, 2008.

FARACO, C. A. Linguagem \& diálogo: as ideias linguísticas do Círculo de Bakhtin. São Paulo: Parábola Editorial, 2009.

INSTITUTO VLADIMIR HERZOG. 12 nov. 2020. Facebook: institutovladimirherzog.br. Disponível em: shorturl.at/wBLMO. Acesso em: 18 ago. 2021.

SOUZA, G. T.. Introdução à teoria do enunciado concreto do círculo Bakhtin/ Volochinov/Medvedev. 2002. 149 f. Dissertação (Mestrado) - São Paulo: Humanitas/FFLCH/USP, 2002

VOLOSHINOV, V. N.. A palavra na vida e a palavra na poesia: introdução ao problema da poética sociológica. In: VOLOSHINOV, V.N. A construção da Enunciação e Outros ensaios. Tradução de João Wanderley Geraldi. São Carlos: Pedro \& João Editores, 2013. p. $71-100$.

VOLOSHINOV, V. N. Slovo v zhizni i slovo v poesie. Zvezda, n. 6, 1926.

VOLOSHINOV, V, N.; BAKHTIN, M.. Discurso na vida e discurso na arte. (sobre poética sociológica). Tradução de Calos Alberto Faraco e Cristóvão Tezza [para fins didáticos]. [2019?]. Versão da língua inglesa de I. R. Titunik a partir do original russo.

\section{(1) $\circledast \circledast$}

Recebido em 31/03/2021. Aceito em 22/05/2021. 